\title{
Multistage Effort and the Equity Structure of Venture Investment Based on Reciprocity Motivation
}

\author{
Chuan Ding, ${ }^{1}$ Jiacheng Chen, ${ }^{2}$ Xin Liu, ${ }^{3}$ and Junjun Zheng ${ }^{4}$ \\ ${ }^{1}$ Institute of Financial Mathematics, Southwestern University of Finance and Economics, Chengdu 610074, China \\ ${ }^{2}$ School of Finance, Southwestern University of Finance and Economics, Chengdu 610074, China \\ ${ }^{3}$ Department of Accounting, Tianfu College of Southwest University of Finance and Economics, Mianyang 621000, China \\ ${ }^{4}$ School of Economics and Management, Wuhan University, Wuhan 430072, China
}

Correspondence should be addressed to Chuan Ding; dingchuan@swufe.edu.cn

Received 27 April 2015; Revised 17 August 2015; Accepted 26 August 2015

Academic Editor: Alicia Cordero

Copyright (C) 2015 Chuan Ding et al. This is an open access article distributed under the Creative Commons Attribution License, which permits unrestricted use, distribution, and reproduction in any medium, provided the original work is properly cited.

\begin{abstract}
For venture capitals, it is a long process from an entry to its exit. In this paper, the activity of venture investment will be divided into multistages. And, according to the effort level entrepreneurs will choose, the venture capitalists will provide an equity structure at the very beginning. As a benchmark for comparison, we will establish two game models on multistage investment under perfect rationality: a cooperative game model and a noncooperative one. Further, as a cause of pervasive psychological preference behavior, reciprocity motivation will influence the behavior of the decision-makers. Given this situation, Rabin's reciprocity motivation theory will be applied to the multistage game model of the venture investment, and multistage behavior game model will be established as well, based on the reciprocity motivation. By looking into the theoretical derivations and simulation studies, we find that if venture capitalists and entrepreneurs both have reciprocity preferences, their utility would have been Pareto improvement compared with those under perfect rationality.
\end{abstract}

\section{Introduction}

Venture capitals have been playing a crucial role in new unlisted SMEs for a long time, especially in new high-tech enterprises. For example, in America, venture capital institutions invest $70 \%$ of their capitals into high-tech industries dominated by IT. Many successful high-tech enterprises, such as Microsoft and Netscape, all once received support during their development by venture capitals. According to our data, in China, $29.27 \%$ of venture capital institutions focus on high-growth fields, and $16.75 \%$ of them focus on high-tech areas. Venture capital is risky simultaneously, even though it is vital to the economic development. Therefore, how to maintain and increase the value of venture capital has been a significant study field for scholars. Scholars target designing a certain kind of financial contracts to motivate venture entrepreneurs (later denoted as EN) to pay more effort that will improve the venture projects' success probability. However, several problems arise. Firstly, the efforts and actions of EN are implicit; thus there is no contracts to motivate all the efforts of EN, so how to make up for this defect? The actions that financial contracts cannot include can be resolved through mutual reciprocal affection. Such research is inspired by practice. For example, CEO quietly prepared for an employee a birthday party (the cost of which is not included in the wage contract), thus leading to the staff's willing to pay more efforts to the CEO. Employees' paying more effort will thus naturally improve the output and, therefore, both the CEO and employees will benefit from it. This reciprocal behavior, in behavioral economics, is called the theory of reciprocal fairness preference. There are many other examples in which reciprocity theory has been applied to improve the performance of enterprises examples; such cases are outstanding in South Korea, Japan, and China. There also exists such a situation in a venture capital: venture capitalist (later denoted as VC) paid the fixed income to EN, and EN will increase efforts to repay VC; therefore, the mutual reciprocal of both $\mathrm{VC}$ and $\mathrm{EN}$ improves the utility of both sides. Secondly, in general VC prefers multistage investment to venture projects. This is because VC 
will continue investment if the venture project is of good quality, and will withdraw from the project if the project fails. Thirdly, VC and EN's reciprocity need to be extended into the long term. Therefore, in this paper we will study the venture investment's decision-making from two perspectives: multistages and the reciprocal fairness preference as well.

\section{Literature Review}

Maintaining and increasing the value of venture capital was an important task in the management of venture capital, VCs hoped to choose venture projects which had good prospects in the future and also hoped to select the qualified enterprise and the manager operated the venture capital to make it appreciated. However, at the beginning of venture capital, the VCs usually did not clearly know the ENs' management ability, the effort level, and the return and risk condition of the project. As a result, they often made decisions according to the principle of maximizing their own benefit, such as capital abuse and over investment, which result in moral hazard problem [1-8]. Given this situation, designing an appropriate equity contract was necessary for the VC to control moral hazard. Aiming to ensure that the EN's effort benefited the $\mathrm{VC}$, the equity contract realized benefit and risk sharing between both sides through coordination mechanism [13, 9-11]. Sahlman [10] believed that the VC should offer incentive restrictions to the $\mathrm{EN}$ based on the observed information, so that the expected benefit of both sides could converge. Shleifer and Vishny [11] argued that if control rights of venture capital institutions were mainly assigned to minor shareholders, the VC's benefit, to some extent, could be protected against potential losses, but it simultaneously might cause the issue of insider control.

According to current literatures on venture capital, staged financing could mitigate moral hazard [12]. Dahiya and Ray [12] thought that the $\mathrm{VC}$ regarded staging as a mechanism. Staged financing provided the VC with the option of ending projects with low early returns. This sorted ventures into two groups: stay or quit. It was efficient to quit if the early returns were weak and to stay otherwise. If the EN's early output was low, the VC and the EN might not work hard; instead they collected their respective outside options. Venture capital usually experienced several rounds of investment from seed capital to final exit, which was a long-term process. Amit et al. [13] and Gompers and Lerner [14] researched the multistage issue on venture capital. Neher [15] believed that upfront financing was feasible in early time, but once the investment was sunk, the EN was insolvent to deal with the VC's claim. However, staged financing could solve these problems because early rounds of investment created collateral for later financing. Ramy and Arieh [9] studied the relationship between the VC and the EN, and offered a multistage game model based on moral hazard. The model considered the EN's effort in different stages and designed a multistage incentive contract to mitigate moral hazard. Research showed that the VC should postpone the EN's incentive, and the optimal form of contract was debt financing. Since Ramy and Arieh [9] only researched the single moral hazard of the EN and ignored the moral hazard of the VC, Zhang and Wei [16] made an improvement, considering double moral hazard and the effort of both sides in different stages. They deduced the optimal incentive contract, analyzed several factors affecting the contract design, and worked out the optimal exit point for the VC. Jin et al. [8] supposed that the output function was the function of the effort in each stage, and they studied the VC's financing problem in two stages.

Early researches only considered the efforts of EN and established the principal-agent model called a unilateral moral hazard model to motivate EN to pay more efforts. However, the success of the project required both EN's expertise and the need for VC's rich experience in marketing. Therefore, both sides needed to pay more efforts. As with the previous analysis, EN and VC might hide their efforts, which might lead to the double moral hazard, and some scholars had established a double moral hazard model. Based on Ramy and Arieh's research, Zhang and Wei [16] took the double moral hazard into consideration and next were able to get the design of the contract in multistage investment. Wu et al. [17] thought personal bounded rationality and the uncertainty of the future benefits of the investment project made VCs and ENs face the risk of double moral hazard; they divided the venture capital project into early days and the development product market stage. De Bettignies and Brander [18] examined the EN's choice between bank finance and venture capital. With venture capital finance, there was a two-sided moral hazard problem as both EN and VC provided unverifiable effort. The EN benefited from the VC's managerial input but must surrender partial ownership of the venture, thus diluting the EN's incentive to provide effort. In incomplete contracts framework, De Bettignies [19] thought the EN could design contracts contingent on three possible control right allocations: entrepreneur control, investor control, and joint control, with each allocation inducing different effort levels by both the EN and the investor. There were other rich results; see $[1,20]$.

From above, we might see that the efforts of VC and EN could be divided into the single moral hazard and the double moral hazard in the management of venture capital.

Then, these research literatures on multistage venture capital were all involved with a hypothesis: the VC and the EN were both perfectly rational. In recent years, many researchers had been challenging this hypothesis of traditional economics. They argued that not all the behaviors could be explained by utility maximization of neoclassical economics; that is, decision-makers were bounded rationality. The behavior of decision-makers with bounded rationality could be presented in many aspects, and one of them was reciprocity motivation. Ultimatum game, dictator game, giftexchange game, trust game, and the empirical study of researchers all clearly showed that participants' fair preference was very compelling. Since fair preference motivation had not been subordinated to theoretical frame work of mainstream economics, many new theoretical models were based on it.

Fairness preference was mainly from two aspects. First, players concerned about whether the final outcome was fairness or not. Fehr and Schmidt [21] proposed simple linear utility function model, the characteristics of the model 
were that the player was faced with trade-off between his own interests and the other player's interests; that is to say, players would maximize its utility in the material benefits and the distribution results of fairness preference. Second, these theoretical models were mainly Rabin's [22] reciprocity motivation theory, and it was also called reciprocity intention. Reciprocity motivation means the following. (1) In response to friendly actions, people would like to sacrifice their own benefits to help them. (2) Conversely, in response to hostile actions, people would like to sacrifice their own benefits to punish them. (3) The lower the cost of sacrifice was, the stronger the power of (1) and (2) was [22]. Rabin [22] believed that people often reacted to others' actions (friendly or hostile). If they perceived the kindness of others, they themselves would like to be friendly in return, that is, returning the favor. Conversely, they would punish others (tit for tat) even if they had to pay for it. Rabin's theory undoubtedly made a ground breaking contribution. Rabin's theoretical model was the first to accurately describe the behavior process based on reciprocity intention and to discuss the significance of this behavior. Based on the F-S [21] model, there had been many research results [23-25]; in this paper, we only considered the influence of reciprocity preference on venture investment. Related research was as follows.

Fehr and Falk [26] proved that it would lower the agent's effort level if we adopted pure material incentives to an agent with reciprocity motivation. Fehr and Fischbacher [27] found that the incentive contract which was optimal for pure self-interest people had a worse effect on the agent with reciprocity motivation instead. On the contrary, the incentive contract which behaved poorly for pure self-interest people had a stronger incentive for the agent with reciprocity motivation. Falk and Ichino [28] and Bartling and Von Siemens [29] found that nonpreference for pure self-interest could improve the team's effort level and promote the level of collaboration among team members and reduce the free-rider problem. Wei and $\mathrm{Pu}$ [30] studied the problem of choices between positive incentive and negative incentive and complete contract incentive and incomplete contract incentive under reciprocity motivation. $\mathrm{Pu}$ [31] successfully incorporated Rabin's idea into classical principal-agent model, assuming that the principal knew that the agent was irrational and presented a property of reciprocity in behavior; when the principal sacrificed his own interests to give more benefits to the agent, the agent would be willing to sacrifice his own interests to return the principal's kindness. $\mathrm{Pu}$ [32] introduced Rabin's model [22] which considered the utility function of both material well-being and reciprocity motivation into existing principal-agent model and derived a new principal-agent model in which the agent's behavior represented reciprocal and irrational. These studies mainly incorporated reciprocity motivation into the existing principal-agent model.

How did reciprocity motivation affect the behavior of the decision-makers? Based on the sequential reciprocity game model of Dufwenberg and Kirchsteiger [33], Wan et al. [34] confirmed that manager's credible behavior had a potent incentive effect on employees with reciprocity. Shi and $\mathrm{Pu}$ [35] investigated the incentive effect when participants had reciprocity preference in different information condition according to sequential reciprocity model. Results clearly showed that, under complete information, when the agent had sufficient reciprocity preference, the principal would give up enforceable contracts and give the agent more options. When the principal had a reciprocity preference, the agent would have motivation to satisfy the principal before the final game, and this motivation would effectively induce the agent to work hard. While under incomplete information, compared with the optimal case under the rational assumption, the introduction of reciprocity preference could make it possible for the principal to improve his material utility without reducing the agent's effort level. To study the dynamic incentive effect of managers' reciprocity preference on employees in two periods, $\mathrm{Pu}$ and Shi [36] built a two-stage sequential game model based on the behaviors of reciprocal principals and employees with interest conflicts. The result showed that, under the circumstance of dynamic strategy, reciprocity still had significant incentive effect. Reciprocity preference of managers would force employees' optimal strategy selection to converge locally, and to some extent it replaced the contract in effect, and the principal's benefit under certain conditions would be greater than that under rational conditions.

Recently, the amount of literatures about venture capital under bounded rationality was small. Fairchild [37] built a behavior game model to study the choice of entrepreneurs between angel investment and venture capital. Zheng and $\mathrm{Wu}$ [24] thought that in the venture capital market, the VCs and the ENs presented bounded rationality in the contract design, especially the ENs. In addition to revenue, the ENs might also take individual leisure requirement, personal fairness preference, and other factors into account. What they were pursuing was satisfactory solution rather than the optimal solution. Aiming at venture investors and venture capitalists with fairness preferences, Zheng and $\mathrm{Xu}$ [25] built a new payment pattern. By designing an effective incentive mechanism, they provided a basis for venture capitalists' establishing a reasonable payment contract. However, none of the prior theoretical papers considered the reciprocity motivation.

This paper focuses on designing behavior capital contracts based on reciprocity motivation through introducing reciprocity motivation theory into the design of multistage venture capital contract. Our starting point is mainly based on the following three aspects. First, multistage venture capital is pervasive in practice. Instead of providing all the investment upfront, the VC invests in stages to control risks and makes refinancing decisions according to the project condition. There are some research results currently, but further study is still needed. Second, in practice, the VC and the EN are bounded rationality, and reciprocity motivation is also a common psychological preference. If the EN inputs more effort, the VC may offer a higher share in return. Of course, this reciprocity is bilateral. Third, majority of research results study the design of capital structure contracts under perfectly rationality and derive corresponding utility or returns. Thus, if we can find a capital structure contract under reciprocity motivation in which the utility or returns of both sides are Pareto improvement of perfect rationality, our 
research perspective will have more practical and theoretical significance.

Our main ideas are as follows. If the VC cooperates with the EN, the EN's effort will achieve the optimal. We call the effort in this case the first-best. Therefore, the first step is to calculate the first-best solution of optimal effort during the cooperation. Then secondly, we calculate the optimal decision of both sides under perfect rationality in the assumption that the two parties make their decisions independently. We call the solution here the second-best. The first-best solution is the optimal upper limit of both sides and the second-best solution is the lower limit of both sides. The third step is to construct a multistage game model on venture capital based on reciprocity motivation through introducing Rabin's [22] model.

We have two goals. The first is to find the optimal effort level between the first-best solution and the second-best solution and to confirm that the capital structure contract is also between the first-best and the second-best solution. The second goal is to confirm that, under reciprocity motivation, the utility or returns of both sides are Pareto improvement compared with that under perfect rationality.

This paper proceeds as follows. In the next section, we put forward the assumptions, notations, and basic descriptions of the model. As a basis for comparison, we consider the multistage decision-making model and solutions under perfect rationality in Section 3. Sections 4 and 5 are, respectively, the theory and the construction of the reciprocity motivation preferences utility function. Section 6 is the solution of the venture capital decision-making model under reciprocity motivation. Given the complexity of the model, we use simulation to confirm the existence of the venture capital incentive contract under reciprocity motivation in Section 7. Finally, Section 8 concludes the paper and directions for future research are proposed.

\section{Model Description and Assumptions}

3.1. Model Description. Consider an innovative entrepreneur (EN) who relies on a venture capitalist (VC) for investment. The VC provides a capital contract for the EN. If the EN accepts, the contract will be executed. If not, the EN's reservation utility will be zero. We assume that both the EN and the VC are risk neutral. The VC stages the investment into $n$ periods to control risks and mitigate moral hazard. And the VC has the option to continue or exit at each end of the period. The effort of the EN is different in different periods. And the more the effort EN inputs, the higher the success rate of the project is. The VC's goal is to select a capital structure contract to maximize his utility, while the EN's goal is to choose an effort level to maximize his utility. Time line of game is depicted in Figure 1.

\subsection{Research Assumptions}

Assumptions 1. We assume that both the EN and the VC are risk neutral. That is, they have equivalent risk tolerance facing possible profit. The EN's decision goal is to maximize the

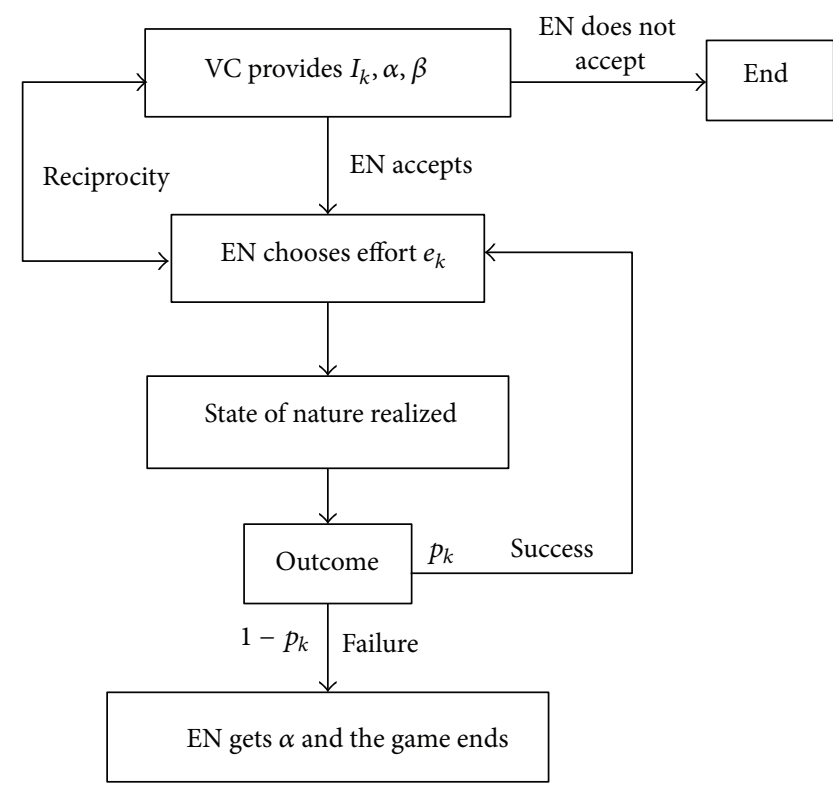

FIGURE 1: The time line.

utility in revenue; the VC's decision goal is to maximize the utility of capital gains.

Assumptions 2. VC invests capital to the venture company. It is a long-term process and the venture capital is divided into $n$ stages, $(n \geq 2)$.

Assumptions 3. If the $\mathrm{VC}$ and the EN reach the investment agreement, the VC will provide the external capital $I_{k},\left(I_{k} \geq\right.$ 0 ), in stage $k, k=1,2,3, \ldots, n$. The average market return rate of external capital $I_{k}$ is $r, 0<r<1$. Thus, the capital cost for the $\mathrm{VC}$ is $(1+r) I_{k}$.

Assumptions 4. It is a long-term process after the VC inputs capital to the venture enterprise. The effort of the EN is different in different periods. Naturally, venture investment should be carried out in stages. So we divide the long-term partnership into $n$ stages, $(n \in N)$. The EN's effort is $e_{k}$, $k=1,2,3, \ldots, n$, in stage $k, k=1,2,3, \ldots, n$. We can regard effort cost as monetary cost. For simplicity, we assume that the effort cost for the $\mathrm{EN}$ is $c\left(e_{k}\right)=b e_{k}^{2} / 2, b \geq 0$. One property of this function is that the cost will increase as the effort increases and the increasing is faster and faster; that is, $c^{\prime}\left(e_{k}\right)>0, c^{\prime \prime}\left(e_{k}\right)>0$.

Assumptions 5. The probability of success is $p, 0 \leq p \leq 1$ after $n$ periods. The success of the venture project is related to EN's effort. The more the effort EN inputs, the greater the probability of success is, and the success in stage $k$ is inseparable from the early effort. So we assume that $p_{k}=$ $e_{1} e_{2} \cdots e_{k}, 0 \leq p_{k}=e_{1} e_{2} \cdots e_{k}=\prod_{i=1}^{k} e_{i} \leq 1$. Let $S$ be the project's return (a fixed cash flow) if the project is successful until stage $k$. In the multiperiod model, the probability of project success or failure can be represented by the past efforts of EN; similar studies can be referred to in Yang's 


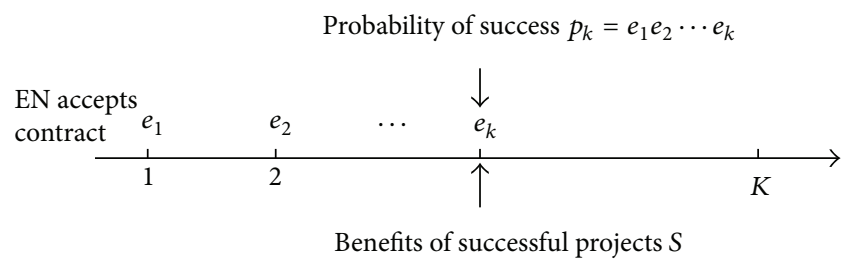

FIGURE 2: Success after $k$-stage.

method [38]. However, the Yang's model is a continuous-time model, while our model is a discrete-time model. Figure 2 shows the success probability and return of venture projects.

For simplicity, we assume that the return in every period is equal; that is, $S \geq 0$. The return is 0 if the project is failed until stage $k$. So the expected return of the project in stage $k$ is

$$
V_{k}=p_{k} S_{k}+(1-p) 0=p_{k} S_{k}=S \prod_{i=1}^{k} e_{i}
$$

Assumptions 6. After the VC invests the capital, at the beginning of the project, the VC gives fixed income $\alpha$ and the revenue sharing coefficient $\beta(0 \leq \beta \leq 1)$ in each period to the $\mathrm{EN}$. We call $(\alpha, \beta)$ the equity contract on investment; $(\alpha, \beta)$ are also known as financial contracts. If EN accepts contract, EN and VC have long-term game relationship; if EN refuses it, the game is over.

Assumptions 7. For simplicity, there is no consideration for the time value of the return. We can also assume that venture capitalist's discount factor is $\delta_{C}$ and the venture entrepreneur's discount factor is $\delta_{E}$. It will increase the complexity of model, but will not affect the conclusions.

\section{Decision Model and Solution of Multistage under Perfect Rationality}

Let $\pi$ be the profit of the EN. Given the fixed income $\alpha$, the return in each stage $\beta V_{k}$, and the total effort cost $\sum_{k=1}^{n} c\left(e_{k}\right)=$ $\sum_{k=1}^{n}\left(b e_{k}^{2} / 2\right)$, the expected profit of the $\mathrm{EN}$ is

$$
\begin{aligned}
\pi & =\alpha+\sum_{k=1}^{n} \beta V_{k}-\sum_{k=1}^{n} \frac{b e_{k}^{2}}{2} \\
& =\alpha+\sum_{k=1}^{n}\left[\beta S \prod_{i=1}^{k} e_{i}\right]-\sum_{k=1}^{n} \frac{b e_{k}^{2}}{2} .
\end{aligned}
$$

The EN chooses effort level in each stage, $e_{1}, e_{2}, \ldots, e_{n}$, to maximize the utility; namely,

$$
\max _{e_{1}, e_{2}, \ldots, e_{n}} \alpha+\sum_{k=1}^{n}\left[\beta S \prod_{i=1}^{k} e_{i}\right]-\sum_{k=1}^{n} \frac{b e_{k}^{2}}{2} .
$$

Since the VC is risk neutral, VC's expected utility equals the expected return:

$$
\begin{aligned}
\Pi & =-\alpha+\sum_{k=1}^{n}(1-\beta) V_{k}-\sum_{k=1}^{n}(1+r) I_{k} \\
& =-\alpha+\sum_{k=1}^{n}\left[(1-\beta) S \prod_{i=1}^{k} e_{i}\right]-\sum_{k=1}^{n}(1+r) I_{k} .
\end{aligned}
$$

The VC chooses appropriate equity contract $(\alpha, \beta)$ to maximize the expected utility. The maximization problem is

$$
\max _{\alpha, \beta}-\alpha+\sum_{k=1}^{n}\left[(1-\beta) S \prod_{i=1}^{k} e_{i}\right]-\sum_{k=1}^{n}(1+r) I_{k} .
$$

4.1. The Optimal Decision of Cooperation. The EN and the VC realize cooperation through one side completely controlling project; that is, the owner of the project and the provider of the investment are the same decision-maker. Consequently, adding (2) to (4), we derive

$$
\Pi^{C}=\sum_{k=1}^{n}\left[S \prod_{i=1}^{k} e_{i}\right]-\sum_{k=1}^{n} \frac{b e_{k}^{2}}{2}-\sum_{k=1}^{n}(1+r) I_{k} .
$$

The decision-maker chooses effort level in each stage, $e_{1}, e_{2}, \ldots, e_{n}$, to maximize the overall utility; namely,

$$
\max _{e_{1}, e_{2}, \ldots, e_{n}} \sum_{k=1}^{n}\left[S \prod_{i=1}^{k} e_{i}\right]-\sum_{k=1}^{n} \frac{b e_{k}^{2}}{2}-\sum_{k=1}^{n}(1+r) I_{k}
$$

We derive the optimal solution $e_{k}^{C *}=(S / b)^{1 /(n-2)}$.

4.2. The Optimal Decision of Noncooperation. Under noncooperation, the VC and the EN make independent decisions to maximize their own utility or return. The VC's goal is the maximization of the future return. Thus, the VC designs a capital structure contract to maximize the total return at the end of stage $n$ :

$$
\max _{\alpha, \beta}-\alpha+\sum_{k=1}^{n}\left[(1-\beta) S \prod_{i=1}^{k} e_{i}\right]-\sum_{k=1}^{n}(1+r) I_{k} .
$$

However, the EN also cares about the future utility maximization while focusing on maximizing the current utility [39]. That means the EN will choose the maximum effort level $e_{1}$ to maximize the return $\alpha+\beta e_{1} S-b e_{1}^{2} / 2$ in stage 1 . Then, in stage 2, the EN will choose the maximum effort level $e_{2}$ to maximize the total return $\alpha+\beta \prod_{k=1}^{2} e_{k} S-\sum_{k=1}^{2}\left(b e_{k}^{2} / 2\right)$ of the two stages.

In stage $n$, the EN will choose the maximum effort level $e_{n}$ to maximize the total return $\alpha+\beta \prod_{k=1}^{n} e_{k} S-\sum_{k=1}^{n}\left(b e_{k}^{2} / 2\right)$ of the former $n$ stages. 
In this game, the VC provides capital structure contract firstly, and then the EN chooses his own effort level. Therefore, this game is Stackelberg game. It can be described as follows (I):

$$
\begin{array}{ll}
\max _{\alpha, \beta} & -\alpha+\sum_{k=1}^{n}\left[(1-\beta) S \prod_{i=1}^{k} e_{i}\right]-\sum_{k=1}^{n}(1+r) I_{k} \\
\text { s.t. } & \max _{e_{1}} \alpha+\beta e_{1} S-\frac{b e_{1}^{2}}{2} \\
& \max _{e_{2}} \alpha+\beta \prod_{k=1}^{2} e_{k} S-\sum_{k=1}^{2} \frac{b e_{k}^{2}}{2} \\
& \vdots \\
& \max _{e_{n}} \alpha+\beta \prod_{k=1}^{n} e_{k} S-\sum_{k=1}^{n} \frac{b e_{k}^{2}}{2} .
\end{array}
$$

In model (I), the first-order condition about $e_{1}, e_{2}, \ldots, e_{n}$ in (10a), (10b), and (10c) is

$$
\begin{aligned}
\beta S & =b e_{1}, \\
\beta S e_{1} & =b e_{2}, \ldots, \beta S \prod_{k=1}^{n-1}=b e_{n} .
\end{aligned}
$$

By introducing the first-order condition to model (I), the VC's problem becomes

$$
\begin{array}{cl}
\max _{\alpha, \beta} & -\alpha+\sum_{k=1}^{n}\left[(1-\beta) S \prod_{i=1}^{k} e_{i}\right]-\sum_{k=1}^{n}(1+r) I_{k} \\
\text { s.t. } & \beta S=b e_{1}, \\
& \beta S e_{1}=b e_{2}, \ldots, \beta S \prod_{k=1}^{n-1}=b e_{n} .
\end{array}
$$

Put formula (13) into objective function (12); we derive the following:

$$
\max _{\alpha, \beta}-\alpha+\frac{S^{\left(n^{2}+n+2\right) / 2}}{b^{n(n+1) / 2}}(1-\beta) \beta^{n(n+1) / 2}-\sum_{k=1}^{n}(1+r) I_{k} .
$$

From formula (14), the first-order condition about $\alpha$ and $\beta$ is

$$
\begin{aligned}
& \alpha^{*}=0, \\
& \beta^{*}=\frac{n^{2}+n}{n^{2}+n+2} .
\end{aligned}
$$

Note 1. In (15), specially, when $n=1, \beta=1 / 2$, this would tie in exactly with a one-period single-sided moral hazard model; the VC, with no value-creating ability, would give half of the equity to the EN to motivate the EN. To be sure, VC has no value-creating ability; why does VC give half of the equity to the EN? The reasons are as follows. (1) VC's investment needs to be paid, and EN's projects and efforts need to be rewarded because the model's parameters are set differently, the result is precisely $\beta=1 / 2$. (2) Our results have some differences with Fairchild [37], which is because the modeling mechanism is different. We are sure that Fairchild [23, 37, 40] provides a lot of important research results in the field of venture capital.

Therefore, the EN's optimal effort level in each stage is

$$
e_{k}^{*}=\frac{S^{k}}{b^{k}} \frac{\left(n^{2}+n\right)^{k}}{\left(n^{2}+n+2\right)^{k}}, \quad k=1,2, \ldots, n .
$$

Put (15) and (16) into the function, we derive

$$
\begin{aligned}
\pi_{\mathrm{VC}}^{*} & =\frac{2 S}{n^{2}+n+2} \prod_{k=1}^{n} \frac{S^{k}}{b^{k}} \frac{\left(n^{2}+n\right)^{k}}{\left(n^{2}+n+2\right)^{k}} \\
& =\frac{2 S}{n^{2}+n+2}\left[\frac{S}{b} \frac{\left(n^{2}+n\right)}{\left(n^{2}+n+2\right)}\right]^{n(n+1) / 2}, \\
\pi_{E}^{*} & =\frac{\left(n^{2}+n\right) S}{n^{2}+n+2} \prod_{k=1}^{n}\left[\frac{S^{k}}{b^{k}} \frac{\left(n^{2}+n\right)^{k}}{\left(n^{2}+n+2\right)^{k}}\right] \\
& -\frac{b}{2} \sum_{k=1}^{n}\left[\frac{S^{k}}{b^{k}} \frac{\left(n^{2}+n\right)^{k}}{\left(n^{2}+n+2\right)^{k}}\right]^{2} \\
& =\frac{\left(n^{2}+n\right) S}{n^{2}+n+2}\left[\frac{S}{b} \frac{\left(n^{2}+n\right)}{\left(n^{2}+n+2\right)}\right]^{n(n+1) / 2} \\
& -\frac{b S^{2}\left(n^{2}+n\right)^{2}\left\{1-\left[S\left(n^{2}+n\right) /\left(n^{2}+n+2\right)\right]^{2 n}\right\}}{2\left[b^{2}\left(n^{2}+n+2\right)^{2}-S^{2}\left(n^{2}+n\right)^{2}\right]} .
\end{aligned}
$$

So there is Proposition 1.

Proposition 1. If the VC cooperates with the EN, the EN's optimal effort level is $e_{k}^{C *}=(b / S)^{1 /(n-2)}$ (first-best). If the $V C$ and the EN make decisions independently, the EN's optimal effort level is $e_{k}^{*}=\left(S^{k} / b^{k}\right)\left(\left(n^{2}+n\right)^{k} /\left(n^{2}+n+2\right)^{k}\right)$ (secondbest). The optimal venture capital structure contract is $\alpha^{*}=0$, $\beta^{*}=\left(n^{2}+n\right) /\left(n^{2}+n+2\right)$. The optimal benefits on both sides, respectively, are as follows:

$$
\begin{aligned}
\pi_{V C}^{*} & =\frac{2 S}{n^{2}+n+2}\left[\frac{S}{b} \frac{\left(n^{2}+n\right)}{\left(n^{2}+n+2\right)}\right]^{n(n+1) / 2}, \\
\pi_{E}^{*} & =\frac{\left(n^{2}+n\right) S}{n^{2}+n+2}\left[\frac{S}{b} \frac{\left(n^{2}+n\right)}{\left(n^{2}+n+2\right)}\right]^{n(n+1) / 2} \\
& -\frac{b S^{2}\left(n^{2}+n\right)^{2}\left\{1-\left[S\left(n^{2}+n\right) /\left(n^{2}+n+2\right)\right]^{2 n}\right\}}{2\left[b^{2}\left(n^{2}+n+2\right)^{2}-S^{2}\left(n^{2}+n\right)^{2}\right]} .
\end{aligned}
$$




\section{The Principle of Reciprocity Motivation Fairness Utility Function}

When studying the decision-making in venture capital, the traditional view assumes that the $\mathrm{VC}$ and the $\mathrm{EN}$ are pure selfinterest. That is, they only pursue their individual maximum benefits rather than care about the fairness of the welfare allocation or behavioral motivation. Yet, a series of game experiments (like ultimatum game, trust game, and giftexchange game) in recent years indicate that fairness preferences also exist in addition to self-interest preferences. The theory believes that they will also focus on the fairness of the welfare allocation or behavioral motivation when they pursue personal interests. As well as the self-interest preferences, fairness preferences can influence the decision-making of the participants in venture capital. For instance, people may sacrifice part of their own interests to preserve the fairness in the revenue allocating, to revenge hostile behaviors or to reward kindness.

The fairness function in venture capital is based on the psychological game framework of Geanakoplos et al. Rabin [22] created a game payoff function through incorporating fairness preferences, which was published in the American economic review. Rabin [22] defined the fairness preferences as a behavior that one rewards others' kindness or punishes others' unkindness. However, how to define the kindness or unkindness specifically? Rabin [22] believed that the behavior of sacrificing your own utility (incomes, interests, and so on) to improve others' utility (incomes, interests, and so on) could be defined as kindness. Similarly, sacrificing your own utility to reduce others' utility could be defined as unkindness. Rabin's framework about fairness preferences incorporated the following three stylized facts. (A) People were willing to sacrifice their own material well-being to help those who were being kind. (B) People were willing to sacrifice their own material well-being to punish those who are being unkind. (C) Both motivations (A) and (B) had a greater effect on behavior as the material cost of sacrificing became smaller. Rabin [22] regarded that these facts could explain not only the behavioral motivation of fairness preference in the ultimatum game but also the one of reciprocity preference in the cooperative game.

Hence, Rabin [22] presented the thoughts in the utility function throughout mathematical models. The first step to incorporate fairness into the analysis was to define a "kindness function" $f_{i}\left(a_{i}, b_{j}\right)$, which measured how kind player $i$ was being to player $j$ or the "distance" between two parties. If player $i$ believed that player $j$ was choosing strategy $b_{j}$, how kind was player $i$ being by choosing $a_{i}$ ? Player $i$ was choosing the payoff pair $\pi_{i}\left(a_{i}, b_{j}\right)$ from among the set of all payoffs feasible $\pi_{i}\left(b_{j}\right)=\left\{\pi_{i}\left(a_{i}, b_{j}\right) \mid a_{i} \in S_{i}\right\}\left(S_{i}\right.$ was the strategy space of player $i$ ) to show the kindness level of player $i$. In Rabin's model, let $\pi_{i}^{\max }\left(b_{j}\right)$ be player $j$ 's highest payoff in $\pi\left(b_{j}\right)$ and let $\pi_{i}^{\min }\left(b_{j}\right)$ be player $j$ 's lowest payoff among points that were Pareto-efficient in $\pi\left(b_{j}\right)$. Then the equitable payoff or fairness payoff could be expressed as

$$
\pi_{j}^{\text {fair }}\left(b_{j}\right)=\frac{\pi_{i}^{\max }\left(b_{j}\right)+\pi_{i}^{\min }\left(b_{j}\right)}{2} .
$$

More generally, it provided a crude reference point against which to measure how generous player $i$ was being to player $j$. From these payoffs, the kindness function was

$$
f_{i}\left(a_{i}, b_{j}\right)=\frac{\pi_{j}\left(a_{i}, b_{j}\right)-\pi_{j}^{\mathrm{fair}}\left(b_{j}\right)}{\pi_{i}^{\max }\left(b_{j}\right)-\pi_{i}^{\min }\left(b_{j}\right)} .
$$

This function captures how much more than or less than player $j$ 's equitable payoff player $i$ believes he is giving to player $j$. If $f_{i}\left(a_{i}, b_{j}\right)$ is positive, it indicates that player $i$ is kind to player $j$, since player $j$ 's actual payoff is higher than the fairness payoff. Otherwise, it indicates that player $i$ is not kind.

Furthermore, Rabin [22] defined

$$
f_{j}\left(b_{j}, c_{i}\right)=\frac{\pi_{i}\left(c_{i}, b_{j}\right)-\pi_{i}^{\mathrm{fair}}\left(c_{i}\right)}{\pi_{i}^{\max }\left(c_{i}\right)-\pi_{i}^{\min }\left(c_{i}\right)} .
$$

This function was to represent player i's beliefs about how kindly player $j$ was treating him, where $c_{i}$ represents player $i$ 's beliefs about what player $j$ believed what player i's strategy was. Because the kindness functions were normalized, the values of $f_{i}\left(a_{i}, b_{j}\right)$ and $f_{j}\left(b_{j}, c_{i}\right)$ must lie in the interval $[-1,1 / 2]$. These kindness functions could now be used to specify fully the players' preferences.

Thus, the reciprocal fairness model [22] was

$$
\begin{aligned}
U_{i}\left(a_{i}, b_{j}, c_{i}\right)= & \pi_{i}\left(a_{i}, b_{j}\right)+f_{j}\left(b_{j}, c_{i}\right) \\
& +f_{j}\left(b_{j}, c_{i}\right) f_{i}\left(a_{i}, b_{j}\right) \\
= & \pi_{i}\left(a_{i}, b_{j}\right)+f_{j}\left(b_{j}, c_{i}\right)\left[1+f_{i}\left(a_{i}, b_{j}\right)\right] .
\end{aligned}
$$

As was shown above, $U_{i}\left(a_{i}, b_{j}, c_{i}\right)$ represents player $i$ 's expected utility, player $i$ not only cared about his material payoff (the first item of the right side of the formula) but also cared treated kindly (the second item of the right side of the formula).

Because these preferences form a psychological game, we could use the concept of psychological Nash equilibrium defined by GPS. This was simply the analog of Nash equilibrium for psychological games, imposing the additional condition that all higher-order beliefs match actual behavior. Rabin [22] called that the solution was "fairness equilibrium."

Definition 2. If the pair of strategies $\left(a_{1}, a_{2}\right) \in S_{1} \times S_{2}$ was a fairness equilibrium, for $i \neq j, i=1,2$,

(1) $a_{i} \in \arg \max _{a_{i} \in S_{i}} U_{i}\left(a_{i}, b_{j}, c_{i}\right)$;

(2) $a_{i}=b_{i}=c_{i}$.

\section{The Construction of Reciprocity Motivation Fairness Utility Function}

According to Rabin's reciprocity fairness preferences theory, we can construct the utility functions of the participants in venture capital based on the fairness preferences. 
Based on Section 2 and practical properties of venture capital, the fairness function is

$$
\begin{aligned}
& \max _{\alpha, \beta}-\alpha+(1-\beta) S \prod_{k=1}^{n} e_{k}, \\
& \pi_{\mathrm{VC}}(\beta)=-\alpha+(1-\beta) S \prod_{k=1}^{n} e_{k}, \\
& \pi_{\mathrm{VC}}^{\max }(\beta)=-\alpha+(1-\beta) S \prod_{k=1}^{n} e_{k}=-\alpha \\
& +(1-\beta) S \prod_{k=1}^{n}\left(\frac{b}{s}\right)^{1 /(n-2)}=-\alpha \\
& +(1-\beta) S^{\left(n^{2}+3 n-4\right) / 2(n-2)} b^{-\left(\left(n^{2}+n\right) / 2(n-2)\right)}, \\
& \pi_{\mathrm{VC}}^{\min }(\beta)=-\alpha, \\
& \pi^{\text {fair }}(\beta)=\frac{\pi_{\mathrm{VC}}^{\max }(\beta)+\pi_{\mathrm{VC}}^{\min }(\beta)}{2} \\
& \quad=\frac{(1-\beta) S^{\left(n^{2}+3 n-4\right) / 2(n-2)} b^{-\left(\left(n^{2}+n\right) / 2(n-2)\right)}}{2}-\alpha .
\end{aligned}
$$

For simplicity, remark $B=S^{\left(n^{2}+3 n-4\right) / 2(n-2)} b^{-\left(\left(n^{2}+n\right) / 2(n-2)\right)}$, where $e_{k}$ and $\beta$ are controlled variables, $0 \leq e_{k} \leq e_{k}^{C *}, 0 \leq$ $\beta \leq 1$, and $e_{k}^{C *}\left(e_{k}^{C *}=(S / b)^{1 /(n-2)}\right)$ denotes the optimal level of cooperation. form:

Substitute the formulas above into (20); there is another

$$
\begin{aligned}
f_{E}(\beta) & =\frac{\pi_{\mathrm{VC}}(\beta)-\pi^{\text {fair }}(\beta)}{\pi_{\mathrm{VC}}^{\max }(\beta)-\pi_{\mathrm{VC}}^{\min }(\beta)} \\
& =\frac{2(1-\beta) S \prod_{k=1}^{n} e_{k}-(1-\beta) B}{2(1-\beta) B} .
\end{aligned}
$$

And then

$$
\begin{aligned}
\pi_{E} & =\alpha+\beta S \prod_{k=1}^{n} e_{k}-\sum_{k=1}^{n} \frac{b e_{k}^{2}}{2}, \\
\pi_{E}^{\max }\left(e_{k}\right) & =\alpha+\beta S \prod_{k=1}^{n} e_{k}-\sum_{k=1}^{n} \frac{b e_{k}^{2}}{2}, \\
\pi_{E}^{\min }\left(e_{k}\right) & =\alpha-\sum_{k=1}^{n} \frac{b e_{\mathrm{k}}^{2}}{2}, \\
\pi_{E}^{\mathrm{fair}}\left(e_{k}\right) & =\frac{\pi_{E}^{\max }\left(e_{k}\right)+\pi_{E}^{\min }\left(e_{k}\right)}{2} \\
& =\frac{1}{2} S \prod_{k=1}^{n} e_{k}+\alpha-\sum_{k=1}^{n} \frac{b e_{k}^{2}}{2} .
\end{aligned}
$$

Continue to substitute the expression into (21); then we have

$$
f_{\mathrm{VC}}\left(e_{k}\right)=\frac{\pi_{E}\left(e_{k}\right)-\pi_{E}^{\text {fair }}\left(e_{k}\right)}{\pi_{E}^{\max }\left(e_{k}\right)-\pi_{E}^{\min }\left(e_{k}\right)}=\frac{2 \beta-1}{2} .
$$

Finally, we put formulas (24) and (26) into Rabin's fairness model (22); then we can derive the utility function of the VC and the EN, respectively,

$$
\begin{aligned}
U_{\mathrm{VC}}= & -\alpha+(1-\beta) S \prod_{k=1}^{n} e_{k}+f_{E}(\beta)\left[1-f_{\mathrm{VC}}\left(e_{k}\right)\right] \\
& -\sum_{k=1}^{n}(1+r) I_{k} \\
= & -\alpha+(1-\beta) S \prod_{k=1}^{n} e_{k} \\
& +\frac{(2 \beta-1)\left[2 S \prod_{k=1}^{n} e_{k}\right]-B}{4 B}, \\
U_{E}= & \alpha+\beta S \prod_{k=1}^{n} e_{k}-\sum_{k=1}^{n} \frac{b e_{k}^{2}}{2}+f_{\mathrm{VC}}\left(e_{k}\right)\left[1-f_{E}(\beta)\right] \\
& -\sum_{k=1}^{n} \frac{b e_{k}^{2}}{2} \\
& +\frac{(2 \beta-1)\left[2 S \prod_{k=1}^{n} e_{k}+B\right]}{4 B} . \\
= & \beta S \prod_{k=1}^{n} e_{k}-\sum_{k=1}^{n} \frac{b e_{k}^{2}}{2} \\
& \\
& \\
& \\
&
\end{aligned}
$$

\section{The Decision-Making Model in Venture Investments and the Solutions}

In Section 4, we construct the utility functions of the VC and the EN based on reciprocity motivation. Similarly, according to the principles of model constructing in Section 4, we can derive another model (III):

$$
\begin{array}{cc}
\max _{\alpha, \beta} & -\alpha+(1-\beta) S \prod_{k=1}^{n} e_{k} \\
& +\frac{(2 \beta-1)\left[2 S \prod_{k=1}^{n} e_{k}\right]-B}{4 B} \\
\text { s.t. } \quad \max _{e_{1}} \alpha+\beta S e_{1}-\frac{b e_{1}^{2}}{2}+\frac{(2 \beta-1)\left(2 S e_{1}+B\right)}{4 B}, & \max _{e_{2}} \alpha+\beta S \prod_{k=1}^{2} e_{k}-\sum_{k=1}^{2} \frac{b e_{k}^{2}}{2} \\
+ & \frac{(2 \beta-1)\left[2 S \prod_{k=1}^{2} e_{k}+B\right]}{4 B},
\end{array}
$$




$$
\begin{aligned}
& \max _{e_{n}} \alpha+\beta S \prod_{k=1}^{n} e_{k}-\sum_{k=1}^{n} \frac{b e_{k}^{2}}{2} \\
& +\frac{(2 \beta-1)\left[2 S \prod_{k=1}^{n} e_{k}+B\right]}{4 B} .
\end{aligned}
$$

In model (III), the first-order condition about $e_{1}, e_{2}, e_{n}$ of (30a), (30b), and (30c) is

$$
\begin{gathered}
\beta S-b e_{1}+\frac{S(2 \beta-1)}{2 B}=0, \\
\beta S e_{1}-b e_{2}+\frac{S(2 \beta-1) e_{1}}{2 B}=0, \\
\vdots \\
\beta S \prod_{k=1}^{n-1} e_{k}-b e_{n}+\frac{S(2 \beta-1) \prod_{1}, \beta S e_{1}=b e_{1} e_{2}, \ldots, 1}{2 B}\left(e_{k}\right) \\
\beta S \prod_{k=1}^{n-1} e_{k}=b e_{n} .
\end{gathered}
$$

There is

$$
\begin{aligned}
& e_{1}^{F *}=\frac{1}{b}\left[\frac{S(2 \beta-1)}{2 B}+\beta S\right], \\
& e_{2}^{F *}=\frac{1}{b^{2}}\left[\frac{S(2 \beta-1)}{2 B}+\beta S\right]^{2}, \ldots, \\
& e_{n}^{F *}=\frac{1}{b^{n}}\left[\frac{S(2 \beta-1)}{2 B}+\beta S\right]^{n} .
\end{aligned}
$$

Put formulas (32) into the objective function (29); we derive the following:

$$
\begin{aligned}
\max _{\alpha, \beta} & -\alpha+(1-\beta) S b^{-n(n+1) / 2}+\left[\beta S+\frac{S(2 \beta-1)}{2 B}\right]^{n(n+1) / 2} \\
- & \sum_{k=1}^{n}(1+r) I_{k} \\
+ & \frac{(2 \beta-1)\left\{2 S b^{-n(n+1) / 2}-[\beta S+S(2 \beta-1) / 2 B]^{n(n+1) / 2}-B\right\}}{4 B} .
\end{aligned}
$$

It is complicated to work out the first-order condition of $(\alpha, \beta)$ in the optimal problems above. Based on reciprocity motivation preferences, we remark both parties' return, respectively, as

$$
\begin{aligned}
& U_{\mathrm{VC}}^{F}=-\alpha+(1-\beta) S b^{-n(n+1) / 2}+\left[\beta S+\frac{S(2 \beta-1)}{2 B}\right]^{n(n+1) / 2} \\
& -\sum_{k=1}^{n}(1+r) I_{k} \\
& +\frac{(2 \beta-1)\left\{2 S b^{-n(n+1) / 2}-[\beta S+S(2 \beta-1) / 2 B]^{n(n+1) / 2}-B\right\}}{4 B} \\
& U_{E}^{F}=\alpha+\beta S b^{-n(n+1) / 2} \\
& +\left[1-\frac{b}{2} b^{-n(n+1)}\right]\left[\beta S+\frac{S(2 \beta-1)}{2 B}\right]^{n(n+1) / 2} \\
& +\frac{(2 \beta-1)\left\{2 S b^{-n(n+1) / 2}-[\beta S+S(2 \beta-1) / 2 B]^{n(n+1) / 2}+B\right\}}{4 B} \text {. }
\end{aligned}
$$

Does we focus on whether there exists an appropriate pair $(\alpha, \beta)$ which can make the profits of both sides higher than the optimal profits under perfect rationality or not? That is, we hope to find out a pair $(\alpha, \beta)$ to satisfy the inequalities $U_{\mathrm{VC}}^{F} \geq$ $\pi_{\mathrm{VC}}^{*}, U_{E}^{F} \geq \pi_{E}^{*}$.

\section{The Simulation Algorithm of Existence with Venture Investment Reciprocity Incentive Contract $(\alpha, \beta)$}

Given too many parameters in formula (33) and the complexity of the model, it is very complicated to work out the solutions directly. We program with Matlab to derive an appropriate $(\alpha, \beta)$ to satisfy the condition $U_{\mathrm{VC}}^{F} \geq \pi_{\mathrm{VC}}^{*}$, $U_{E}^{F} \geq \pi_{E}^{*}$. For simplicity, we just study 3 stages; that is, we take $n=3$. The cost coefficient of the EN is $b=1$. Since the probability $p$ satisfies the condition, $0 \leq p_{k}=e_{1}^{*} e_{2}^{*} \cdots e_{k}^{*}=$ $\left[S\left(n^{2}+n\right) / b\left(n^{2}+n+2\right)\right]^{n(n+1) / 2}$. When we take $n=3, b=1$, there is $0 \leq S \leq 7 / 6$, so the return of the successful project $S=0.8$. If the project's value is $S=7 / 6$, it means the project's success; in order to generality, we take $S=0.8$; it means that the project may succeed or also may fail. Consider $I_{k}=0.5$, $r=0.2$. Substituting them into the utility function, we can simplify the utility function:

$$
\begin{aligned}
\widetilde{U}_{\mathrm{VC}}^{F} & =-\alpha+(1-\beta)(0.8)^{7}\left[\frac{\beta-0.5}{(0.8)^{7}}+\beta\right]^{6} \\
+ & \frac{0.25}{(0.8)^{7}}(2 \beta+1) \\
& \cdot\left\{2(0.8)^{7}\left[\frac{\beta-0.5}{(0.8)^{7}}+\beta\right]^{6}-(0.8)^{7}\right\}-1.8, \\
\tilde{\pi}_{\mathrm{VC}}^{*} & =0.143(0.8)^{7}(0.857)^{6},
\end{aligned}
$$




$$
\begin{aligned}
\widetilde{U}_{E}^{F} & =\alpha+\beta(0.8)^{7}\left[\frac{\beta-0.5}{(0.8)^{7}}+\beta\right]^{6}+0.5(0.8)^{(12)} \\
\cdot & {\left[\frac{\beta-0.5}{(0.8)^{7}}+\beta\right]^{(12)}+\frac{0.25}{(0.8)^{7}}(2 \beta-1) } \\
\cdot & \left\{2(0.8)^{6}\left[\frac{\beta-0.5}{(0.8)^{7}}+\beta\right]^{6}+(0.8)^{7}\right\}, \\
\widetilde{\pi}_{E}^{*} & =(0.686)^{7}-0.444\left[1-(0.686)^{6}\right] .
\end{aligned}
$$

Now the two inequalities $U_{\mathrm{VC}}^{F} \geq \pi_{\mathrm{VC}}^{*}, U_{E}^{F} \geq \pi_{E}^{*}$ can be simplified to

$$
\begin{aligned}
-\alpha & +(1-\beta)(0.8)^{7}\left[\frac{\beta-0.5}{(0.8)^{7}}+\beta\right]^{6}+\frac{0.25}{(0.8)^{7}}(2 \beta+1) \\
\cdot & \left\{2(0.8)^{7}\left[\frac{\beta-0.5}{(0.8)^{7}}+\beta\right]^{6}-(0.8)^{7}\right\}-2160 \\
\geq & 0.143(0.8)^{7}(0.857)^{6} \\
\alpha+ & \beta(0.8)^{7}\left[\frac{\beta-0.5}{(0.8)^{7}}+\beta\right]^{6}+0.5(0.8)^{(12)} \\
\cdot & {\left[\frac{\beta-0.5}{(0.8)^{7}}+\beta\right]^{(12)}+\frac{0.25}{(0.8)^{7}}(2 \beta-1) } \\
& \cdot\left\{2(0.8)^{6}\left[\frac{\beta-0.5}{(0.8)^{7}}+\beta\right]^{6}+(0.8)^{7}\right\} \geq(0.686)^{7} \\
& -0.444\left[1-(0.686)^{6}\right] .
\end{aligned}
$$

For convenience, we remark

$$
\begin{aligned}
g_{1} & =\widetilde{U}_{\mathrm{VC}}^{F}=-\alpha+(1-\beta)(0.8)^{7}\left[\frac{\beta-0.5}{(0.8)^{7}}+\beta\right]^{6} \\
& +\frac{0.25}{(0.8)^{7}}(2 \beta+1)
\end{aligned}
$$

$$
\begin{aligned}
\max _{\alpha, \beta} \quad & \alpha+(1-\beta)(0.8)^{7}\left[\frac{\beta-0.5}{(0.8)^{7}}+\beta\right]^{6}+\frac{0.25}{(0.8)^{7}}(2 \beta+1)\left\{2(0.8)^{7}\left[\frac{\beta-0.5}{(0.8)^{7}}+\beta\right]^{6}-(0.8)^{7}\right\}-1.8 \\
\text { s.t. } \quad & \max \alpha+\beta(0.8)^{7}\left[\frac{\beta-0.5}{(0.8)^{7}}+\beta\right]^{6}+0.5(0.8)^{(12)}\left[\frac{\beta-0.5}{(0.8)^{7}}+\beta\right]^{(12)} \\
& +\frac{0.25}{(0.8)^{7}}(2 \beta-1)\left\{2(0.8)^{6}\left[\frac{\beta-0.5}{(0.8)^{7}}+\beta\right]^{6}+(0.8)^{7}\right\}, \\
- & \alpha+(1-\beta)(0.8)^{7}\left[\frac{\beta-0.5}{(0.8)^{7}}+\beta\right]^{6}+\frac{0.25}{(0.8)^{7}}(2 \beta+1)\left\{2(0.8)^{7}\left[\frac{\beta-0.5}{(0.8)^{7}}+\beta\right]^{6}-(0.8)^{7}\right\}-1.8 \\
\geq & 0.143(0.8)^{7}(0.857)^{6}, \\
\alpha+ & \beta(0.8)^{7}\left[\frac{\beta-0.5}{(0.8)^{7}}+\beta\right]^{6}+0.5(0.8)^{(12)}\left[\frac{\beta-0.5}{(0.8)^{7}}+\beta\right]^{(12)} \\
& +\frac{0.25}{(0.8)^{7}}(2 \beta-1)\left\{2 ( 0 . 8 ) ^ { 6 } \left[\frac{\beta-0.5}{\left.\left.(0.8)^{7}+\beta\right]^{6}+(0.8)^{7}\right\} \geq(0.686)^{7}-0.444\left[1-(0.686)^{6}\right] .}\right.\right.
\end{aligned}
$$

The objective of the research is to find a contract structure $(\alpha, \beta)$, in which the utility of both sides under the reciprocity motivation is greater than that under perfect rationality; that say, $g_{1} \geq g_{2}, h_{1} \geq h_{2}$. Intuitively, there may be several satisfy $g_{1} \geq g_{2}, h_{1} \geq h_{2}$. How to find the hore information. So firstly he will maximize his Uaximize the utility of the $\mathrm{VC}$ $(\max U)$. Thus, the problem is

$$
\begin{array}{ll}
\max _{\alpha, \beta} & \widetilde{U}_{\mathrm{VC}}^{F} \\
\text { s.t. } & \max \widetilde{U}_{E}^{F}, \\
& \widetilde{U}_{\mathrm{VC}}^{F} \geq \widetilde{\pi}_{\mathrm{VC}}^{*}, \\
& \widetilde{U}_{E}^{F} \geq \widetilde{\pi}_{E}^{*} .
\end{array}
$$


We use simulation algorithm to solve the optimization problem. The algorithm is as follows.

Step 1. Let $\alpha$ and $\beta$ lie in the interval $[0,1]$. The initial value of $\alpha$ and $\beta$ is $\alpha=0$ and $\beta=0$, and the step length is 0.01 .

Step 2. Loop over the value of $\alpha$ and $\beta$ to calculate $g_{1}$ and $h_{1}$. If $g_{1}>g_{2}$ and $h_{1}>h_{2}$, go to Step 3. If the loop is end, go to Step 4 .

Step 3. Store the maximum value of $g_{1}$ in the variable "max," and let the initial of Max be negative infinity. Store the value of $g_{1}, \alpha$, and $\beta$ in the $n * 3$ matrix, " $m$." If $g_{1}<\max$, return to Step 2. If $g_{1}=\max$, add a new row to matrix $m$ to store the current value of $[\max , \alpha ; \beta]$ and return to Step 2; if $g_{1}>\max$, replace the value of max with $g_{1}$ and the matrix $m$ and return to Step 2.

Step 4. Search in matrix $m$ to find the maximum value of $g_{1}$ and $h_{1}$; then input $\left(g_{1} ; h_{1}\right)$.

We use Matlab editing program, we can work out that the optimal venture capital structure is $\left(\widetilde{\alpha}^{*}, \widetilde{\beta}^{*}\right)=$ $(1.0000,0.6400)$, optimal utility $\widetilde{U}_{\mathrm{VC}}^{F}=2.2515, \widetilde{U}_{E}^{F}=1.7572$.

Thus, we can conclude Proposition 3.

Proposition 3. In multistage venture capital, if the VC and the EN both have reciprocity motivation, there necessarily exists the optimal capital structure contract $\left(\widetilde{\alpha}^{*}, \widetilde{\beta}^{*}\right)=(1.0000,0.6400)$. The utility of both sides under reciprocity motivation is Pareto improvement compared with that under perfect rationality.

Proposition 3 shows the crucial significance of this paper. The existing literatures in multistage venture capital mainly focus on the case of perfect rationality while we also consider the reciprocity motivation, under which the optimal utilities of both the VC and the EN are Pareto improvement.

Proposition 4. In multistage venture capital, if the VC and the EN both have reciprocity motivation, compared with the standard game, VC changes the payment structure; that is, $\alpha$ increases from 0 to 1 and $\beta$ decreases from 0.85 to 0.64 . At the same time, EN's efforts increases from $e_{k}^{*}$ to $e_{k}^{F *}$, the utility of both sides under reciprocity motivation is Pareto improvement.

Proposition 4 is established as follows. Obviously, according to Proposition $1, \alpha=0, \beta^{*}=\left(n^{2}+n\right) /\left(n^{2}+n+2\right)$, when $n=3$, there is $\beta^{*}=0.85$, and according to Proposition 3, $\left(\widetilde{\alpha}^{*}, \widetilde{\beta}^{*}\right)=(1.0000,0.6400)$.

Owing to

$$
\begin{aligned}
e_{k}^{*} & =\frac{S^{k}}{b^{k}} \frac{\left(n^{2}+n\right)^{k}}{\left(n^{2}+n+2\right)^{k}}, \\
e_{k}^{F *} & =\frac{1}{b^{n}}\left[\frac{S(2 \beta-1)}{2 B}+\beta S\right]^{n}, \quad k=1,2, \ldots, n .
\end{aligned}
$$

The parameter values and the optimal numerical solutions are brought into $e_{k}^{*}, e_{n}^{F *}$,

$$
\begin{aligned}
e_{k}^{*} & =0.686^{k}=(0.174+0.512)^{k} \\
& =\left(\frac{0.112}{0.644}+0.512\right)^{k}, \\
e_{k}^{F *} & =\left(\frac{0.112}{0.8^{7}}+0.512\right)^{k}, \quad k=1,2, \ldots, n .
\end{aligned}
$$

Obviously,

$$
\begin{array}{r}
e_{k}^{F *}=\left(\frac{0.112}{0.8^{7}}+0.512\right)^{k} \geq\left(\frac{0.112}{0.644}+0.512\right)^{k}=e_{k}^{*}, \\
k=1,2, \ldots, n .
\end{array}
$$

Note 2. First, Propositions 3 and 4 are two numerical results that show the existence of the optimal solution of the model. Therefore it cannot guarantee the model's uniqueness, and thus our model does not pursue uniqueness, which is a defect of this paper. Second, Propositions 3 and 4 reflect the significance of this paper, but in practice, there is no such a financial contract that can motivate EN to pay the best first-order effort; but, however, there are also many examples to illustrate the positive role of the reciprocal fairness preference. For example, CEO quietly prepared for an employee a birthday party (the cost of which not included in the wage contract), thus leading to the staff's willing to pay more efforts to the CEO. Employees then pay more effort; naturally the output is improved, and both CEO and employees benefit from this party. In venture capital, there is also such a situation; VC pays the fixed income to EN ( $\alpha$ increases from 0 to 1 ), and EN will increase efforts to repay VC (EN's efforts increases $e_{k}^{*}$ to $e_{k}^{F *}$ ). Although we see that $\beta$ decreases from 0.85 to 0.64 , we can also witness $\alpha$ increases significantly from 0 to 1 ; the final revenue of EN was improved, and the mutual reciprocal of both $\mathrm{VC}$ and EN improves the utility of the two sides.

\section{Conclusive Remarks}

The moral hazard in the venture capital has been a widely concerned problem all over the world. The multistage model in venture capital that scholars considered could mitigate the moral hazard problem. Speaking of the models, some scholars researched how to design an incentive contract using the principal-agent model to ensure the venture capital's appreciation and safety. While some scholars considered the exit of the VC in the multistage problem based on complete information and explained the condition in which the VC will continue or exit, their underlying hypotheses are all perfect rationality.

However, it is impractical for some decision-makers to adopt this perfect rationality hypothesis. In contrast, decision-makers commonly adopt bounded rationality. Therefore, we can say that to study the multistage venture capital model under bounded rationality is of crucial importance. Reciprocity motivation is one of many forms of 
bounded rationality for certain, and it is also a common one in practice.

In this paper, we have incorporated the reciprocity motivation into the multistage model to study the optimal capital structure contract. As a basis for comparison, at first we offered two game models: a cooperative model and a noncooperative one, both under perfect rationality. Then we introduced the reciprocity motivation into the multistage model and built the multistage behavioral game model based on reciprocity motivation. Our study clearly showed that the utility of the VC and the EN under reciprocity motivation is Pareto improvement compared with that under perfect rationality. This is where we exhibited the innovation point of this paper.

However, our study has limitations in the four following aspects. Firstly, our model has been founded under information symmetry; then how to combine our study of the reciprocity motivation with the principal-agent model? Secondly, we have mainly focused on the designing of the optimal capital structure contract but have not given the exit conditions of the VC. Thirdly, the model is based on the risk neutral assumption, so how will the model change if the VC and EN have fairness preferences? Fourthly, we only considered the EN's effort, so what are the results for the EN and VC's efforts? These are valuable challenges in front of us.

\section{Conflict of Interests}

The authors declare that there is no conflict of interests regarding the publication of this paper.

\section{Acknowledgments}

The authors are particularly grateful to the associate editor and reviewers for thoughtful, valuable discussions and suggestions. The authors acknowledge the financial support by Humanities and Social Science Project of Ministry of Education of China (14XJCZH001), by Soft Science Research Project of Sichuan Province (2014ZR0027), and by the Fundamental Research Funds for the Central Universities (JBK130401). They also thank their students Litian Xu, Yiqing Zhao, Qinyu Chen, Mengxing Du, Xiao Xu, Zexi Zhang, Feng $\mathrm{Yu}$, and Huan Zhou; Jiaci Wang contributed to this paper.

\section{References}

[1] C. Casamatta, "Financing and advising: optimal financial contracts with venture capitalists," Journal of Finance, vol. 58, no. 5, pp. 2059-2086, 2003.

[2] K. M. Schmidt, "Convertible securities and venture capital finance," Journal of Finance, vol. 58, no. 3, pp. 1139-1166, 2003.

[3] Y. Chan, D. Siegel, and A. V. Thakor, "Learning, corporate control and performance requirements in venture capital contracts," International Economic Review, vol. 31, no. 2, pp. 365381, 1990.

[4] J.-J. Zheng, P. Zhang, X.-S. Hu, and W.-L. Jiang, "Research on bidding strategy and modeling of equity auction based on stochastic differential equations," System Engineering Theory and Practice, vol. 33, no. 4, pp. 893-900, 2013.
[5] J. J. Zheng, X. Tan, and W. T. Fan, "An incentive model with stocks based on principal-agent theory," Journal of Management Sciences in China, vol. 8, no. 1, pp. 24-29, 2005.

[6] W. X. Guo and Y. Zeng, "Double moral hazard and the theory of capital structure of venture capital financing," Journal of Management Sciences in China, vol. 12, no. 3, pp. 119-131, 2009.

[7] J.-P. Xu and S.-J. Chen, "The study of venture capital's principalagent model based on asymmetric information," System Engineering Theory and Practice, vol. 24, no. 1, pp. 19-24, 2004.

[8] Y. H. Jin, Y. Q. Xi, and Z. X. Ye, "Study of multi-period dynamic financial model of venture capital considering reputation," System Engineering Theory and Practice, vol. 5, no. 8, pp. 76-80, 2003.

[9] E. Ramy and G. Arieh, "A multi-period game theoretic model of venture capitalists and entrepreneurs," European Journal of Operational Research, vol. 144, no. 2, pp. 440-453, 2003.

[10] W. A. Sahlman, "The structure and governance of venturecapital organizations," Journal of Financial Economics, vol. 27, no. 2, pp. 473-521, 1990.

[11] A. Shleifer and R. W. Vishny, "Liquidation values and debt capacity: a market equilibrium approach," The Journal of Finance, vol. 47, no. 4, pp. 1343-1366, 1997.

[12] S. Dahiya and K. Ray, "Staged investments in entrepreneurial financing," Journal of Corporate Finance, vol. 18, no. 5, pp. 11931216, 2012.

[13] R. Amit, J. Brander, and C. Zott, "Venture capital financing of entrepreneurship in Canada," in Capital Markets Issues in Canada, P. Halpern, Ed., pp. 237-277, Industry Canada, Ottawa, Canada, 1997.

[14] P. Gompers and J. Lerner, The Venture Capital Cycle, MIT Press, Cambridge, Mass, USA, 1999.

[15] D. V. Neher, "Staged financing: an agency perspective," Review of Economic Studies, vol. 66, no. 2, pp. 255-274, 1999.

[16] S. D. Zhang and D. X. Wei, "Analysis on multi-stage investment game of double moral hazard in venture capital," Nankai Economics Studies, vol. 54, no. 6, pp. 142-150, 2008.

[17] B. Wu, X. X. Xu, and J. M. He, "Double-side moral hazard and convertible bond design in venture capital firms," Journal of Management Sciences in China, vol. 15, no. 1, pp. 11-20, 2012.

[18] J.-E. De Bettignies and J. A. Brander, "Financing entrepreneurship: bank finance versus venture capital," Journal of Business Venturing, vol. 22, no. 6, pp. 808-832, 2007.

[19] J.-E. De Bettignies, "Financing the entrepreneurial venture," Management Science, vol. 54, no. 1, pp. 151-166, 2008.

[20] R. Repullo and J. Suarez, "Venture capital finance: a security design approach," Review of Finance, vol. 8, no. 1, pp. 75-108, 2004.

[21] E. Fehr and K. M. Schmidt, "A theory of fairness, competition, and cooperation," The Quarterly Journal of Economics, vol. 114, no. 3, pp. 817-868, 1999.

[22] M. Rabin, "Incorporating fairness into game theory and economics," American Economic Review, vol. 83, no. 5, pp. 12811302, 1993.

[23] R. Fairchild, "Fairness norms and self-interest in venture capital/entrepreneur contracting and performance," Management Online Review, 2010.

[24] J. J. Zheng and J. F. Wu, "Research on moral hazard of venture entrepreneur base on the fairness preference," Technology Economics, vol. 29, no. 8, pp. 88-92, 2010. 
[25] J. J. Zheng and M. Y. Xu, "A research into venture financing contract on the basis of fairness preference," Economic Review, no. 1, pp. 14-18, 2010.

[26] E. Fehr and A. Falk, "Psychological foundations of incentives," European Economic Review, vol. 46, no. 4-5, pp. 687-724, 2002.

[27] E. Fehr and U. Fischbacher, "Why social preferences matterthe impact of non-selfish motives on competition, cooperation and incentives," Economic Journal, vol. 112, no. 478, pp. C1-C33, 2002.

[28] A. Falk and A. Ichino, "Clean evidence on peer effects," Journal of Labor Economics, vol. 24, no. 1, pp. 39-57, 2006.

[29] B. Bartling and F. A. Von Siemens, "Inequity aversion and moral hazard with multiple agents," Working Paper, Mimeo, University of Munich, Munich, Germany, 2004.

[30] G. X. Wei and Y. J. Pu, "Fairness preference and tournament incentives," Management Science, vol. 19, no. 2, pp. 47-54, 2006.

[31] Y. J. Pu, "A model incorporating fairness into principal-agent: a contribution from behavior economics," Contemporary Finance and Economics, vol. 268, no. 3, pp. 5-11, 2007.

[32] Y. J. Pu, "A principal-agent model with fairness," China Economic Quarterly, vol. 7, no. 1, pp. 298-318, 2007.

[33] M. Dufwenberg and G. Kirchsteiger, "A theory of sequential reciprocity," Games and Economic Behavior, vol. 47, no. 2, pp. 268-298, 2004.

[34] D. F. Wan, J. H. Luo, and J. F. Zhao, “The managerial trustworthy behavior and employee's effort level-based on a two stages sequential reciprocity game model," Systems Engineering, vol. 7, no. 1, pp. 101-106, 2009.

[35] W. Shi and Y. J. Pu, "Dynamic reciprocity effect based on different information conditions," Journal of System Engineering, vol. 28, no. 1, pp. 167-179, 2013.

[36] Y. J. Pu and W. Shi, "Reciprocity incentive effects based on the perspective of conict of interest," Journal of Systems Engineering, vol. 28, no. 1, pp. 28-37, 2013.

[37] R. Fairchild, "An entrepreneur's choice of venture capitalist or angel-financing: a behavioral game-theoretic approach," Journal of Business Venturing, vol. 26, no. 3, pp. 359-374, 2011.

[38] J. Yang, “An entrepreneur's choice of venture capitalist or angelfinancing: a behavioral game-theoretic approach," Management Sciences, vol. 56, no. 9, pp. 1568-1583, 2010.

[39] M. Wu and S. Y. Lai, "The study of effect on venture entrepreneur's persistent efforts to venture investment decisionmaking," Journal of Industrial Engineering and Engineering Management, vol. 27, no. 4, pp. 22-32, 2013.

[40] R. Fairchild, "Financial contracting between managers and venture capitalists: the role of value-added services, reputation seeking, and bargaining power," Journal of Financial Research, vol. 27, no. 4, pp. 481-495, 2004. 


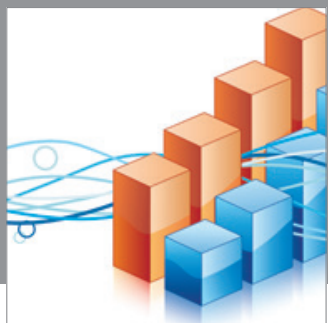

Advances in

Operations Research

mansans

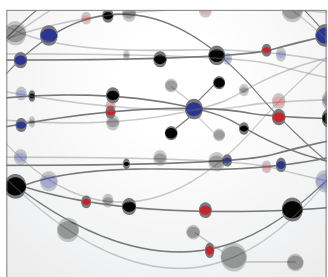

The Scientific World Journal
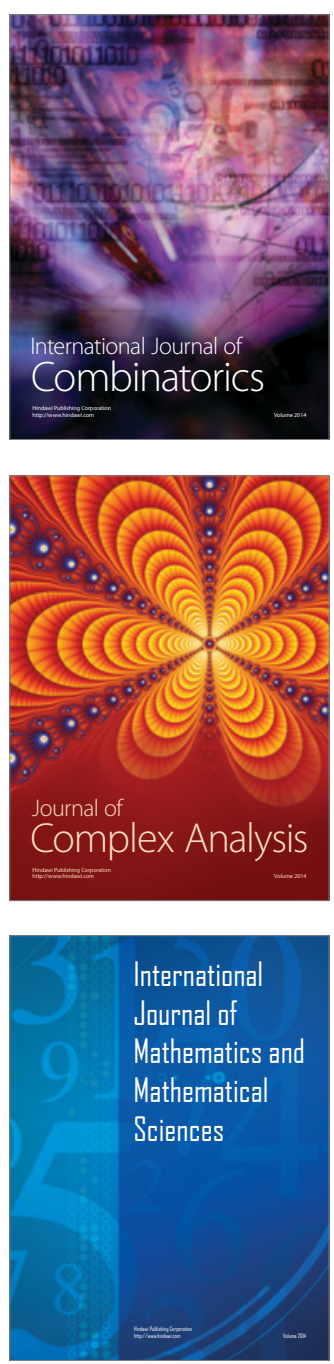
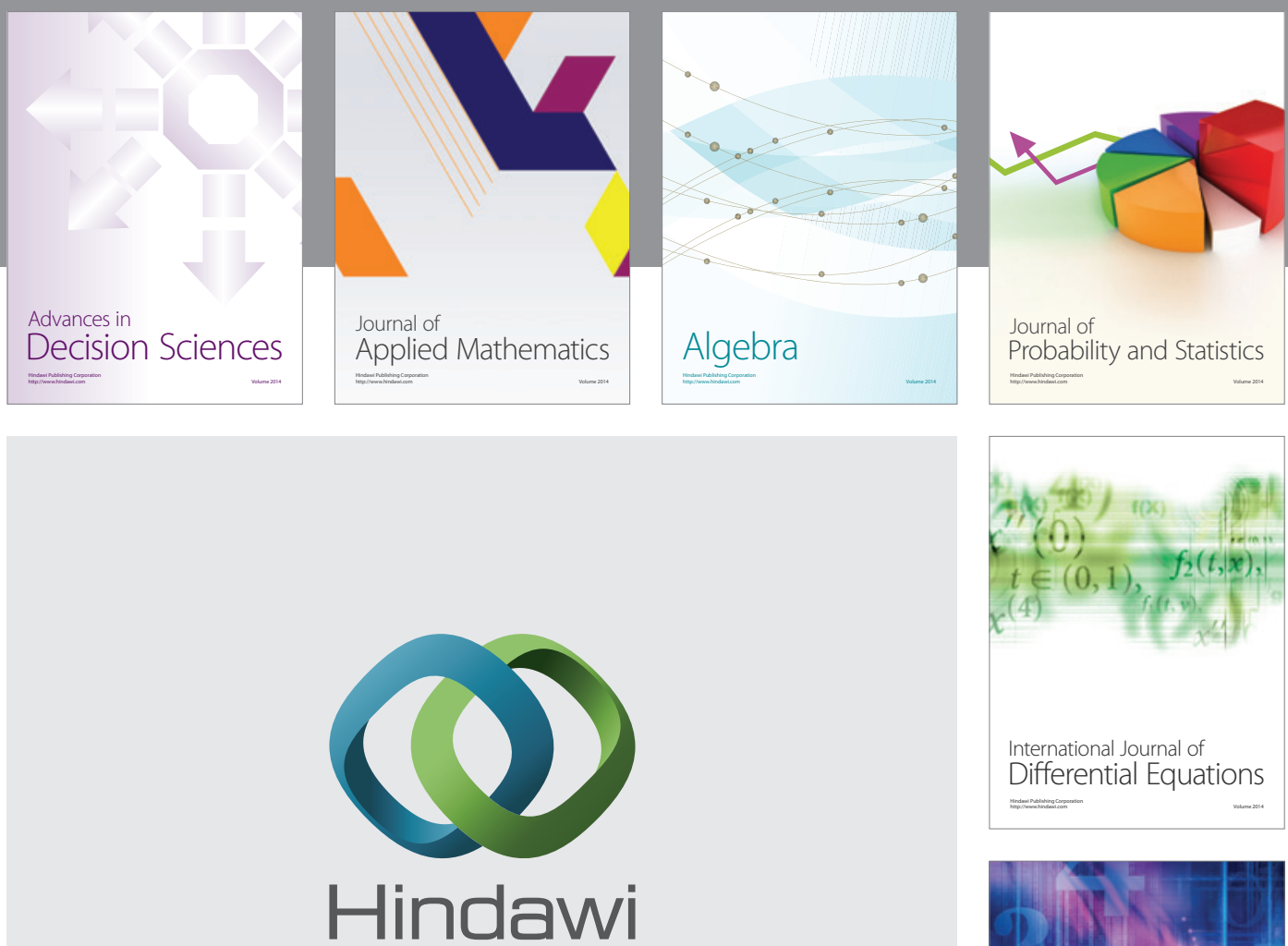

Submit your manuscripts at http://www.hindawi.com
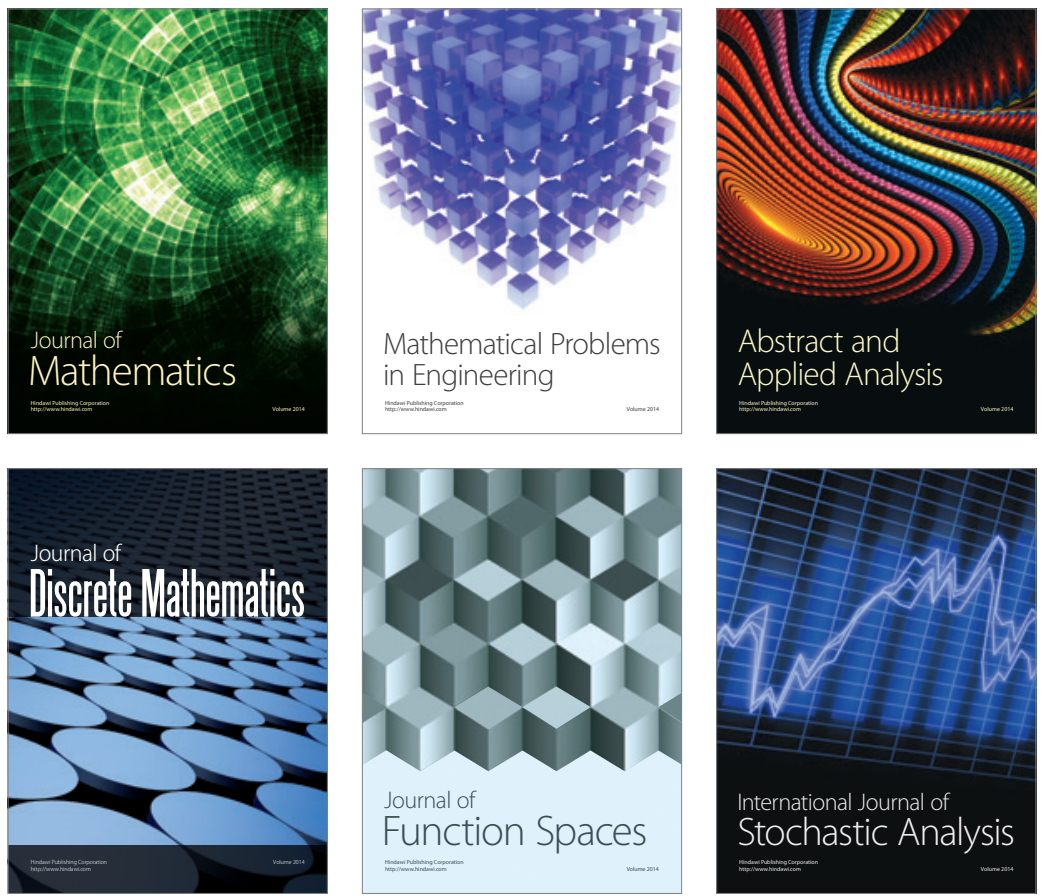

Journal of

Function Spaces

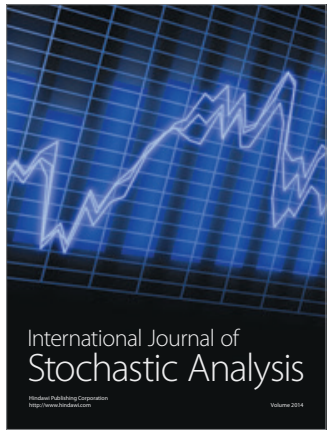

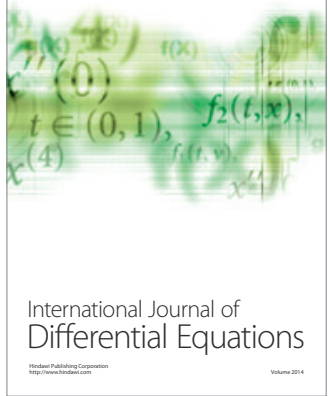
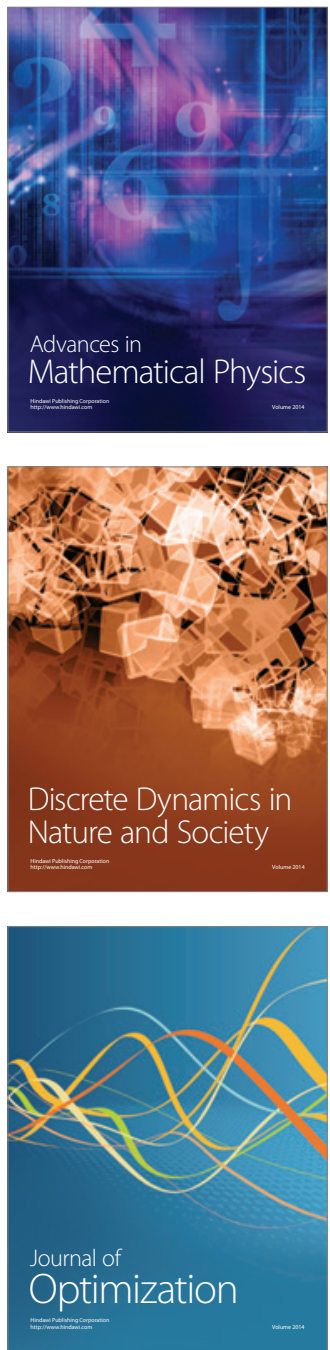